\title{
The Efficacy of Unilateral Use of a Blood Reinfusion Device in One-Stage Bilateral Total Knee Arthroplasty
}

\author{
Geon-Hyeong Kim, MD, Se-Wook Park, MD, Jong-Ho Kim, MD, and Yong In, MD \\ Department of Orthopaedic Surgery, Seoul St. Mary’s Hospital, The Catholic University of Korea College of Medicine, Seoul, Korea
}

Purpose: To assess the efficacy of unilateral use of a blood reinfusion device in one-stage bilateral total knee arthroplasty (TKA).

Materials and Methods: We carried out a retrospective cohort study on 100 patients having one-stage bilateral TKA. In 50 of these patients (study group), a blood reinfusion device was applied on one knee and a standard suction drain on the other, and they were compared with 50 matched controls who received bilateral suction drains (control group). The hemoglobin ( $\mathrm{Hb}$ ) level, the hematocrit (Hct) and the platelet count were checked preoperatively, immediately postoperatively, and the third and seventh days postoperatively. The total drain output and the amount of allogeneic blood transfusion were also compared.

Results: There were no significant differences in the total drain output and required amount of allogeneic blood transfusions between groups ( $\mathrm{p}>0.05$ ). However, the study group had significantly lower $\mathrm{Hb}$ and $\mathrm{Hct}$ values by the first day postoperatively and significantly lower platelet count values by the third day postoperatively than the control group $(\mathrm{p}<0.05)$.

Conclusions: Compared with use of bilateral suction drains, unilateral use of reinfusion device was not advantageous in reducing allogeneic transfusion in one-stage bilateral TKA.

Keywords: Knee, Arthroplasty, Reinfusion, Blood transfusion

\section{Introduction}

Although osteoarthritis (OA) of the knee is often bilateral, there have been controversies about performing bilateral total knee arthroplasty (TKA) in a single stage ${ }^{1-3)}$. Considerable amount of bleeding occurs in sequential or simultaneous bilateral $\mathrm{TKA}^{2,4,5}$. Allogeneic blood transfusions have been commonly used to compensate for blood loss in such cases ${ }^{1,3}$. However, because of complications and the cost of allogeneic blood transfusions, an alternative method of using an autologous blood reinfusion device has been developed ${ }^{6-8)}$.

Received October 28, 2013; Revised (1st) January 13, 2014;

(2nd) January 22, 2014; Accepted January 24, 2014

Correspondence to: Yong In, MD

Department of Orthopaedic Surgery, Seoul St. Mary’s Hospital, 222

Banpo-daero, Seocho-gu, Seoul 137-701, Korea

Tel: +82-2-2258-2838, Fax: +82-2-535-9834

E-mail: iy1000@catholic.ac.kr

This is an Open Access article distributed under the terms of the Creative Commons Attribution Non-Commercial License (http://creativecommons.org/licenses/by-nc/3.0/) which permits unrestricted non-commercial use, distribution, and reproduction in any medium, provided the original work is properly cited.
Many studies have compared a blood reinfusion device and a standard suction drain in arthroplasty ${ }^{4,-12)}$. While the reinfusion devices reduced the rates of allogeneic transfusion after TKA, most reports are limited to unilateral TKA. Breakwell et al. ${ }^{4)}$ reported that bilateral use of blood reinfusion devices in simultaneous bilateral TKA was safe and effective for reducing allogeneic blood transfusion requirements. However, expensive medical devices are not covered by the national health insurance in some countries. The use of two reinfusion devices in a single stage bilateral TKA can overburden the budget for TKA.

To the best of our knowledge, no study has reported on the effectiveness of the postoperative salvage of blood from a unilateral knee in a single stage bilateral TKA. The purpose of this study was to assess the efficacy of unilateral use of a blood reinfusion device in patients undergoing one stage bilateral TKA. We hypothesized that the use of a blood reinfusion device on a unilateral knee in a patient undergoing bilateral TKA would decrease blood transfusion requirement compared with the bilateral use of suction drains. 


\section{Kim et al. The Efficacy of Unilateral Use of a Blood Reinfusion Device}

\section{Materials and Methods}

This study was approved by the Institutional Review Board of our hospital in Korea. The study group consisted of 50 consecutive patients who underwent one stage bilateral TKA using a blood reinfusion device (ConstaVac CBC II Blood Conservation System; Stryker, Mahwah, NJ, USA) on one knee and a standard suction drain (Zimmer Inc., Warsaw, IN, USA) on the other knee between January and August 2011. All patients consented to the study. We compared them with 50 matched controls who received bilateral standard suction drains in TKA between January 2008 and December 2010 (control group). Patients were matched by gender, age (difference, $\leq 1$ year) and body mass index (BMI; difference, $\leq 0.5 \%$ ). All patients were diagnosed with primary OA on both knees. The records of these patients were reviewed for co-morbidities affecting blood loss. Patients having a history of previous knee surgery, chronic liver disease, chronic renal disease, endocrine disease, bleeding tendency or use of anticoagulant drugs for cardiovascular disease were excluded from the study. Patients taking aspirin were included, but we asked them to stop taking aspirin seven days before surgery. Prothrombin time (PT) in seconds, activated partial thromboplastin time (APTT) in seconds and prothrombin time/international normalized ratio (PT/ INR) were tested preoperatively. Other coagulation factor assays were not checked routinely.

All operations were carried out under general anesthesia by a single surgeon in a sequential manner using a subvastus approach. Cemented, posterior-stabilized prostheses were inserted in all knees. A pneumatic tourniquet was applied and inflated to $300 \mathrm{mmHg}$. Meticulous bleeding control was performed after deflation of the tourniquet. Total tourniquet time and operation time affecting the intraoperative blood loss were recorded in all patients ${ }^{13)}$. The operation was performed on the more painful side first where a standard $400 \mathrm{~mL}$ suction drain was inserted, and the other side was operated subsequently. The same suction drain was inserted into the other knee in the control group patients, whereas the ConstaVac CBC II system in which blood was filtered before being re-infused was used in the study group patients. The drained blood of the reinfusion device was collected during the first 6 postoperative hours and reinfused intravenously according to the manufacturer's instructions. We turned the vacuum adjustment dial symbol to medium $(50 \mathrm{mmHg}$ ) to set the vacuum level of the ConstaVac CBC II system because the blood was drained at the pressure of 25 to $60 \mathrm{mmHg}$ by the standard suction drain. Pressure generation by drains decreased as the drained blood increased ${ }^{144}$. In all knees, only one deep drain was connected to the suction drain or reinfusion device. Doctors and nurses in the operation room, recovery room and ward were well educated on how to use the device. All drains were removed at 48 hours after surgery. Allogeneic blood transfusion was indicated for patients with the hemoglobin $(\mathrm{Hb})$ concentration of below $10 \mathrm{~g} / \mathrm{dL}$ or with clinical signs of anemia, such as fatigue, dyspnea, tachycardia, changes in mental status, or hypotension ${ }^{15)}$. Enoxaparin of $40 \mathrm{mg}$ was administered for thromboprophylaxis. The enoxaparin therapy was initiated 12 hours before surgery and restarted 6 to 8 hours after surgery for 10 consecutive days of administration.

The $\mathrm{Hb}$ level, the hematocrit (Hct) and the platelet count were checked preoperatively, immediately postoperatively and the first, third and seventh days postoperatively and compared between groups. The total drain output and the amount of allogeneic blood transfusion were also compared.

The chi-square test, the Fisher's exact test and independent $t$ test were used to compare the results between groups. A $p<0.05$ was considered statistically significant. SPSS ver. 13.0 (SPSS Inc., Chicago, IL, USA) was used for data analysis.

\section{Results}

No statistically significant differences were observed between groups in age, gender, BMI, and comorbidities (Table 1). There were no significant differences in the total tourniquet time and operation time. There were no significant differences in the preoperative values of complete blood count tests, PT, APTT and PT/INR. In the study group, the average amount of blood reinfusion was $341.6 \pm 222.2 \mathrm{~mL}$ (range, 50 to $1,350 \mathrm{~mL}$ ). There were no significant differences in total drain output between groups (Table 2) $(\mathrm{p}=0.111)$. All patients in both groups required allogeneic blood transfusion. No significant differences in the amount of allogeneic blood transfusion were observed between groups (Table 2) $(\mathrm{p}=0.872)$.

The study group had significantly lower Hb, Hct and platelet count values compared with the control group immediately after the surgery and for the first postoperative day $(\mathrm{p}<0.05)$ (Table 2 ). The study group had significantly lower platelet count values than the control group by the third postoperative day. There were no significant differences in $\mathrm{Hb}$, Hct at the third postoperative day and in $\mathrm{Hb}$, Hct, platelet count values at the seventh postoperative day. There were no transfusion reactions, contaminations or wound infections in both groups. 
Table 1. Demographic Data

\begin{tabular}{|c|c|c|c|}
\hline Variable & Study group $(\mathrm{n}=50)$ & Control group $(\mathrm{n}=50)$ & p-value \\
\hline Age (yr) & $65.8 \pm 5.2(54-76)$ & $65.9 \pm 5.2(54-76)$ & 0.969 \\
\hline $\operatorname{Sex}(M / F)$ & $3 / 47$ & $3 / 47$ & 1.000 \\
\hline $\operatorname{BMI}\left(\mathrm{kg} / \mathrm{m}^{2}\right)$ & $26.7 \pm 3.4(20.8-35.2)$ & $26.7 \pm 3.2(20.8-35.2)$ & 0.930 \\
\hline Aspirin therapy & 6 & 3 & 0.487 \\
\hline Hypertension & 20 & 25 & 0.315 \\
\hline Diabetes mellitus & 10 & 10 & 1.000 \\
\hline \multicolumn{4}{|l|}{ Other comorbidities } \\
\hline Endocrine disease $\mathrm{e}^{\mathrm{a})}$ & 0 & 0 & 1.000 \\
\hline Chronic renal disease $^{\mathrm{b})}$ & 0 & 0 & 1.000 \\
\hline Chronic liver disease $^{c)}$ & 0 & 0 & 1.000 \\
\hline Operation length (min) & $175.1 \pm 19.4(139-225)$ & $172.2 \pm 19.7(130-220)$ & 0.891 \\
\hline Tourniquet time (min) & $105.7 \pm 13.8(80-150)$ & $103.2 \pm 14.2(80-130)$ & 0.502 \\
\hline Preop Hb (g/dL) & $13.1 \pm 1.0(11.1-15.4)$ & $13.4 \pm 1.2(10.7-16.0)$ & 0.145 \\
\hline Preop Hct (\%) & $39.2 \pm 2.8(33.2-45.5)$ & $40.1 \pm 3.5(31.2-48.3)$ & 0.177 \\
\hline Preop platelet count $\left(\times 10^{3}\right)$ & $253.2 \pm 46.7(175.0-349.0)$ & $269.8 \pm 61.3(181.0-415.0)$ & 0.133 \\
\hline Preop PT (in seconds) & $104.1 \pm 12.4(72.0-132.0)$ & $109.4 \pm 11.3(86.2-135.0)$ & 0.876 \\
\hline Preop PT/INR & $0.99 \pm 0.05(0.88-1.11)$ & $0.96 \pm 0.05(0.89-1.09)$ & 0.889 \\
\hline Preop APTT (in seconds) & $24.6 \pm 2.6(18.5-31.3)$ & $24.3 \pm 2.7(19.6-30.6)$ & 0.488 \\
\hline
\end{tabular}

Values are presented as mean \pm SD (range).

BMI: body mass index, Preop: preoperative, Hb: hemoglobin, Hct: hematocrit, PT: prothrombin time, PT/INR: prothrombin time/international normalized ratio, APTT: activated partial thromboplastin time.

${ }^{a)}$ Hypothyroidism, addison's disease, hyperparathyroidism, ${ }^{\text {b) }}$ Polycystic renal disease, chronic renal failure, transplanted kidney, ${ }^{\text {c) }}$ Chronic hepatitis, alcoholic liver disease, liver cirrhosis, storage diseases, tumors.

Table 2. Comparison of Results Between Groups

\begin{tabular}{|c|c|c|c|}
\hline Variable & Study group $(\mathrm{n}=50)$ & Control group $(n=50)$ & $\mathrm{p}$-value \\
\hline Total drain $(\mathrm{mL})$ & $1,512.6 \pm 473.6(750-3,175)$ & $1,671.7 \pm 513.5(550-2,780)$ & 0.111 \\
\hline Allogeneic transfusion (mL) & $1,979.4 \pm 822.3(640-4,000)$ & $1,955.6 \pm 643.1(640-3,200)$ & 0.872 \\
\hline Postop Hb (g/dL) & $11.0 \pm 1.1(8.8-14.2)$ & $11.9 \pm 1.4(8.1-14.6)$ & 0.001 \\
\hline Hct (\%) & $32.8 \pm 3.4(26.4-41.0)$ & $35.3 \pm 4.4(23.8-45.1)$ & 0.002 \\
\hline Platelet count $\left(\times 10^{3}\right)$ & $177.5 \pm 47.2(88.0-356.0)$ & $203.1 \pm 52.8(127.0-369.0)$ & 0.012 \\
\hline POD1 $\mathrm{Hb}(\mathrm{g} / \mathrm{dL})$ & $10.0 \pm 1.0(7.8-12.0)$ & $10.8 \pm 1.3(9.1-13.6)$ & 0.001 \\
\hline Hct (\%) & $29.7 \pm 2.9(22.9-36.0)$ & $31.9 \pm 4.1(25.6-40.4)$ & 0.003 \\
\hline Platelet count $\left(\times 10^{3}\right)$ & $148.0 \pm 38.7(82.0-262.0)$ & $172.1 \pm 38.0(101.0-261.0)$ & 0.002 \\
\hline POD3 Hb (g/dL) & $9.9 \pm 1.1(7.0-14.1)$ & $10.1 \pm 1.3(7.2-13.4)$ & 0.381 \\
\hline Hct (\%) & $29.3 \pm 3.2(20.3-41.4)$ & $29.8 \pm 4.1(21.3-40.6)$ & 0.521 \\
\hline Platelet count $\left(\times 10^{3}\right)$ & $133.3 \pm 41.5(85.0-326.0)$ & $154.1 \pm 37.5(89.0-246.0)$ & 0.010 \\
\hline POD7 Hb (g/dL) & $10.8 \pm 0.8(9.2-12.5)$ & $10.8 \pm 0.9(9.2-12.9)$ & 0.822 \\
\hline Hct (\%) & $32.5 \pm 2.3(27.1-37.3)$ & $32.1 \pm 3.1(26.7-39.4)$ & 0.490 \\
\hline Platelet count $\left(\times 10^{3}\right)$ & $202.0 \pm 67.0(89.0-425.0)$ & $196.5 \pm 54.8(107.0-331.0)$ & 0.655 \\
\hline
\end{tabular}

Values are presented as mean \pm standard deviation (range).

Postop: postoperative, $\mathrm{Hb}$ : hemoglobin, Hct; hematocrit, POD1: the 1st day postoperatively, POD3: the 3rd day postoperatively, POD7: the 7th day postoperatively. 


\section{Kim et al. The Efficacy of Unilateral Use of a Blood Reinfusion Device}

\section{Discussion}

In general, blood loss is greater in single stage bilateral TKA than in unilateral TKA. Cohen et al. ${ }^{5)}$ reported on the postoperative blood loss in bilateral TKA versus unilateral TKA. The average postoperative drainage through a standard suction drain was measured as $692 \mathrm{~mL}$ for bilateral TKA and $442 \mathrm{~mL}$ for unilateral TKA, and they reported a high prevalence of allogeneic blood transfusion in the bilateral TKA group. Fabi et al. ${ }^{16)}$ retrospectively analyzed 150 patients with unilateral TKA versus 150 patients with simultaneous bilateral TKA. The transfusion rate in the bilateral TKA group was almost four times greater than that in the unilateral TKA group. More studies reported significantly high rates of allogeneic blood transfusions in patients undergoing bilateral TKA ${ }^{4,17}$.

With the objective of reducing allogeneic blood transfusion, the reinfusion device is an alternative method whereby people receive their own blood for transfusion ${ }^{18,19)}$. Several studies reported that the use of a blood reinfusion device reduced allogeneic blood transfusions in arthroplasty ${ }^{4,7-12)}$. However, most of these studies were conducted among patients using a blood reinfusion device in a unilateral TKA. Breakwell et al. ${ }^{4}$ reported that an average of $1000 \mathrm{~mL}$ of drainage blood was salvaged with bilateral use of blood reinfusion devices in simultaneous bilateral TKA. In the present study, we investigated the efficacy of unilateral use of a blood reinfusion device in patients undergoing one stage bilateral TKA. In our study, all patients required allogeneic blood transfusion regardless of the use of a reinfusion device.

In most countries, the health insurance system is controlled by the government. In Korea, the expense of the use of a blood reinfusion device in unilateral TKA is not covered by the Health Insurance Review \& Assessment Service, whereas the use of one blood reinfusion device in one stage bilateral TKA is. We questioned whether the unilateral use of a blood reinfusion device in one stage bilateral TKA would be effective in terms of reducing allogeneic blood transfusion and costs. Our study was the first retrospective cohort study to assess the efficacy of unilateral use of a blood reinfusion device in bilateral TKA. Unilateral use of a reinfusion device in one stage bilateral TKA was not effective in reducing the amount of allogeneic blood transfusion compared to the bilateral use of suction drains. In addition, the use of a reinfusion device can be controversial in terms of cost effectiveness ${ }^{4,819)}$. The exact risk of transfusion related problems, such as disease transmission and transfusion reaction, is difficult to quantify. A reinfusion device would cost about 160 US dollars when covered by the health insurance. Suppose that the reinfusion leads to a significant corresponding reduction in the amount of allogeneic transfusion. In our study, the average amount of blood reinfusion was $341.6 \mathrm{~mL}$, equivalent to about one unit of packed red cells ( 400 $\mathrm{mL}$ per one unit). The total cost of one unit of $400 \mathrm{~mL}$ packed red cells including $\mathrm{ABO}$ and Rhesus blood typing and antibody screening test was approximately 55 US dollars when covered by the health insurance in Korea. It did cost more to use the reinfusion device than to transfuse allogeneic blood into a patient.

Even until the first postoperative day, the Hb level, Hct level and platelet count were significantly lower in the study group than in the control group. de Jong et al. ${ }^{20)}$ and Zacharopoulos et al. ${ }^{8)}$ described similar findings based on the analysis of drain blood in reinfusion device and having a blood test after surgery. We have thought of a few reasons why our study found conflicting results. It was probably because reinfusion of the drained blood was started after six postoperative hours at the earliest. Blood was washed out of the body and into the drains even during the reinfusion. We also thought that the reinfused blood was not the same as the patient's venous blood in terms of blood quality. Leukocyte and platelet counts were reduced in the drained blood $^{6}$. Other studies have shown that the drain blood had low platelet counts, low $\mathrm{pH}$ and a reduction of clotting factors along with increased fibrin degradation products ${ }^{6,72-23)}$. Therefore, the reinfused blood may activate coagulation in the recipient and decrease platelet counts ${ }^{15,20)}$. In our study, the study group had lower postoperative $\mathrm{Hb}$, Hct and platelet count values compared with the control group. We thought there were changes in blood quality in the drained blood and the reinfused blood may have caused an activation of coagulation and fibrinolysis and additional hemolysis ${ }^{24,25}$. Safety of a blood reinfusion device in patients undergoing orthopaedic surgery is controversial ${ }^{18,26}$. However, in our study, there were no significant differences in $\mathrm{Hb}, \mathrm{Hct}$, and platelet counts at the seventh postoperative day. There were no clinical evidence of coagulation, or hemolysis related phenomena in both groups. Therefore, additional studies are required to assess clinical safety of blood reinfusion devices.

In this study, allogeneic blood transfusion was indicated when the $\mathrm{Hb}$ concentration was below $10 \mathrm{~g} / \mathrm{dL}$ or clinical signs of anemia were present. Most TKA patients are elderly who may have reduced ability to compensate for acute blood loss. Decision making regarding postoperative allogeneic transfusion is lacking scientific support. Although the ' $10 / 30$ rule $^{\text {,27) }}$ stating that transfusion is necessary in patients with $\mathrm{Hb}$ less than $10 \mathrm{~g} / \mathrm{dL}$ or Hct less than $30 \%$ is considered outdated, we determined an allogeneic transfusion was needed if postoperative $\mathrm{Hb}$ fell below $10 \mathrm{~g} / \mathrm{dL}$. The use of a blood reinfusion device on the second knee in our 
bilateral TKA was based on the report of Bould et al. ${ }^{17)}$ that sequential procedures lead to a greater blood loss from the second knee than the first, due to various factors including hypothermia and depletion of clotting factors.

The present study has several limitations that require consideration. Although the same surgical team applied the same surgical technique and the same transfusion criteria postoperatively, this study involved only a small number of patients. But in order to reduce confounding factors that affect blood loss, we retrospectively compared with a matched group. Second, many confounding variables may have influenced the hematologic results. We think that the input volume of intravenous fluid, sampling site and time, and time of allogeneic transfusion could have the potential to influence laboratory findings. We did not take confounding variables into consideration, but we learned about the trend in the hematologic change after transfusion. Third, it would be difficult to generalize the cost effectiveness of reinfusion devices from our study. Health insurance systems differ from country to country and hidden costs related to complications of transfusion were not factored in. Forth, we did not measure the amount of intra-operative blood loss. The total blood loss is the intra-operative bleeding plus the post-operative drainage. It is difficult to calculate the amount of blood loss into the tissues, residual blood in the knee and blood loss due to hemolysis, all of which are hidden ${ }^{28)}$. There is a variety of formulas to estimate the blood loss during arthroplasty using height, weight and pre- and post-operative Hct, but they all differ with regard to accuracy ${ }^{28,299}$.

\section{Conclusions}

In our study, unilateral use of a reinfusion device led to no significant reduction in allogeneic blood transfusion requirement and yielded no cost effectiveness in patients undergoing one stage bilateral TKA. Bilateral use of blood reinfusion devices is recommended in one stage bilateral TKA to reduce allogeneic blood transfusion.

\section{Conflict of Interest}

No potential conflict of interest relevant to this article was reported.

\section{References}

1. Restrepo C, Parvizi J, Dietrich T, Einhorn TA. Safety of simultaneous bilateral total knee arthroplasty: a meta-analysis. J Bone Joint Surg Am. 2007;89:1220-6.
2. Ritter MA, Harty LD. Debate: simultaneous bilateral knee replacements: the outcomes justify its use. Clin Orthop Relat Res. 2004;(428):84-6.

3. Yoon HS, Han CD, Yang IH. Comparison of simultaneous bilateral and staged bilateral total knee arthroplasty in terms of perioperative complications. J Arthroplasty. 2010;25:17985.

4. Breakwell LM, Getty CJ, Dobson P. The efficacy of autologous blood transfusion in bilateral total knee arthroplasty. Knee. 2000;7:145-7.

5. Cohen RG, Forrest CJ, Benjamin JB. Safety and efficacy of bilateral total knee arthroplasty. J Arthroplasty. 1997;12:497502.

6. Dalen T, Brostrom LA, Engstrom KG. Autotransfusion after total knee arthroplasty: effects on blood cells, plasma chemistry, and whole blood rheology. J Arthroplasty. 1997;12:51725.

7. Singh VK, Singh PK, Javed S, Kumar K, Tomar J. Autologous transfusion of drain contents in elective primary knee arthroplasty: its value and relevance. Blood Transfus. 2011;9:281-5.

8. Zacharopoulos A, Apostolopoulos A, Kyriakidis A. The effectiveness of reinfusion after total knee replacement: a prospective randomised controlled study. Int Orthop 2007;31:303-8.

9. Cushner FD, Scott WN, Scuderi G, Hill K, Insall JN. Blood loss and transfusion rates in bilateral total knee arthroplasty. J Knee Surg. 2005;18:102-7.

10. Han CD, Shin DE. Postoperative blood salvage and reinfusion after total joint arthroplasty. J Arthroplasty. 1997;12:5116.

11. Munoz M, Ariza D, Garceran MJ, Gomez A, Campos A. Benefits of postoperative shed blood reinfusion in patients undergoing unilateral total knee replacement. Arch Orthop Trauma Surg. 2005;125:385-9.

12. Woolson ST, Wall WW. Autologous blood transfusion after total knee arthroplasty: a randomized, prospective study comparing predonated and postoperative salvage blood. J Arthroplasty. 2003;18:243-9.

13. Prasad N, Padmanabhan V, Mullaji A. Blood loss in total knee arthroplasty: an analysis of risk factors. Int Orthop. 2007;31:39-44.

14. Grobmyer SR, Graham D, Brennan MF, Coit D. High-pressure gradients generated by closed-suction surgical drainage systems. Surg Infect (Larchmt). 2002;3:245-9.

15. Practice Guidelines for blood component therapy: a report 
by the American Society of Anesthesiologists Task Force on Blood Component Therapy. Anesthesiology. 1996;84:73247.

16. Fabi DW, Mohan V, Goldstein WM, Dunn JH, Murphy BP. Unilateral vs bilateral total knee arthroplasty risk factors increasing morbidity. J Arthroplasty. 2011;26:668-73.

17. Bould M, Freeman BJ, Pullyblank A, Newman JH. Blood loss in sequential bilateral total knee arthroplasty. J Arthroplasty. 1998;13:77-9.

18. Guan ZP, Jiang J, Lv HS, Wang N. Research on coagulation of unwashed shed blood after total knee replacement in Chinese patients. Artif Cells Blood Substit Immobil Biotechnol. 2008;36:51-62.

19. Lakshmanan P, Purushothaman B, Sharma A. Impact of reinfusion drains on hemoglobin level in total knee arthroplasty. Am J Orthop (Belle Mead NJ). 2010;39:70-4.

20. de Jong M, Ray M, Crawford S, Whitehouse SL, Crawford RW. Platelet and leukocyte activation in salvaged blood and the effect of its reinfusion on the circulating blood. Clin Orthop Relat Res. 2007;456:238-42.

21. Jensen CM, Pilegaard R, Hviid K, Nielsen JD, Nielsen HJ. Quality of reinfused drainage blood after total knee arthroplasty. J Arthroplasty. 1999;14:312-8.

22. Kristiansson M, Soop M, Saraste L, Sundqvist KG, Suontaka AM, Blomback M. Cytokine and coagulation characteristics of retrieved blood after arthroplasty. Intensive Care Med.
1995;21:989-95.

23. Peter VK, Radford M, Matthews MG. Re-transfusion of autologous blood from wound drains: the means for reducing transfusion requirements in total knee arthroplasty. Knee. 2001;8:321-3.

24. Reents W, Babin-Ebell J, Misoph MR, Schwarzkopf A, Elert O. Influence of different autotransfusion devices on the quality of salvaged blood. Ann Thorac Surg. 1999;68:58-62.

25. Rosolski T, Mauermann K, Fastnacht J, Hergert M. The quality of blood obtained with direct autotransfusion systems is poor! [Internet]. Park Ridge, IL: ASA; 2003 [cited 2014 Feb 11]. Available from: http://www.asaabstracts.com/.

26. Sebastian C, Romero R, Olalla E, Ferrer C, Garcia-Vallejo JJ, Munoz M. Postoperative blood salvage and reinfusion in spinal surgery: blood quality, effectiveness and impact on patient blood parameters. Eur Spine J. 2000;9:458-65.

27. Stehling L, Simon TL. The red blood cell transfusion trigger. Physiology and clinical studies. Arch Pathol Lab Med. 1994;118:429-34.

28. Sehat KR, Evans R, Newman JH. How much blood is really lost in total knee arthroplasty?. Correct blood loss management should take hidden loss into account. Knee. 2000;7:151-5.

29. Gibon E, Courpied JP, Hamadouche M. Total joint replacement and blood loss: what is the best equation? Int Orthop. 2013;37:735-9. 